\title{
Effect of surfactants on the yield stress of cement paste
}

\author{
Blandine Feneuil, Olivier Pitois, Nicolas Roussel" \\ Laboratoire Navier, UMR 8205, École des Ponts ParisTech, IFSTTAR, CNRS, UPE, Champs-sur-Marne, France
}

\section{A R T I C L E I N F O}

\section{Keywords:}

Surfactant

Rheology (A)

Adsorption (C)

Cement paste (D)

Pore solution (B)

\begin{abstract}
A B S T R A C T
Although many surfactant molecules are available to produce stable aqueous foams, these molecules can strongly interact with cement grains. We focus therefore here on the interactions between various surfactants and cement grains in order to identify some selection criteria for surfactants dedicated to foam cement production. First, we check the surfactant ability to produce aqueous foam in synthetic cement pore solution. Then, we observe that most surfactants do adsorb on cement grains, inducing concentration-dependent effects on the yield stress of cement paste. Our results suggest that, for some of these surfactants, the yield stress increases significantly as inter-particle hydrophobic attractive forces develop at the surface of the grains. However, above a concentration threshold, those attractive forces sharply drop because of the formation of surface micelles acting as steric barriers between particles, which results in a strong decrease in yield stress
\end{abstract}

\section{Introduction}

Cement foams are promising materials. Indeed, addition of air into cement paste may offer, besides substantial material savings, improved thermal properties. This is why, since several years, the study of aerated cementitious materials has become an active field of research. In order to control cement foam morphology, the destabilization mechanisms of fresh cement foams, until cement hardening, must be stopped or slowed. Stabilization can be achieved by monitoring rheological properties of the fresh cement paste, especially its yield stress [1-3].

Most formulations of cement foams include chemicals known as surfactants. Surfactants can either enhance air entrainment into cement paste (air entraining agents) during fast stirring of the cement slurry, or they can be used to create a pre-formed aqueous foam which is later incorporated into the cement slurry. In both processes, surfactants remain in the cement paste and may thus affect the rheological and early age properties of the cement matrix.

Besides cement foams, surfactants can be used as air entraining agents in frost-resistant concrete and as shrinkage reducing admixtures [4].

In this study, we consider the interaction of surfactants with a cement paste. We first investigate the effect of a synthetic pore solution on the foaming ability of these surfactants. Then, we measure the effect of surfactant addition on the yield stress of the cement paste. Our results show the major role played by the amounts of surfactant adsorbed at the surface of the cement grains both on fresh cement paste yield stress and on the hydrophobization of the cement grains.

\section{Background}

\subsection{Surfactant molecules in cement paste}

Surfactant molecules are composed of a hydrophilic head and a hydrophobic hydrocarbon tail. In aqueous solution, some surfactant molecules adsorb at the air-water interface, with their hydrophobic tails towards air, which reduces the liquid-air surface tension $\gamma[5,6]$. Above the Critical Micelle Concentration (CMC), the air-water interface becomes saturated with surfactant molecules while residual surfactant molecules in bulk solution gather into elements called micelles. As a consequence, above CMC, liquid-air surface tension does not decrease any more with increasing surfactant concentration as shown in Fig. 1.

The hydrophilic head can either be charged (ionic surfactants) or polar (non-ionic surfactants). Ionic surfactants are said cationic if their charge is positive, anionic if their charge is negative and amphoteric when their head include both types of charge [5,6]. Surfactants enhance foam creation and foam stability through several mechanisms. First, lowering surface tension means that less energy is needed to create air-water interface. Then, layers of surfactant on both sides of the water film separating two bubbles repel each other due to some steric interactions and, in the case of ionic surfactants, some electrostatic interaction. In addition, it was shown that micelles or other structures inside the film may contribute to its stabilization [5]. It is worth noting that dynamics of surfactant adsorption at air-water interface is also an important aspect for foam generation and stability: to stabilize newly formed interfaces, surfactant adsorption must indeed be faster than

\footnotetext{
" Corresponding author.

E-mail address: nicolas.roussel@ifsttar.fr (N. Roussel).
} 


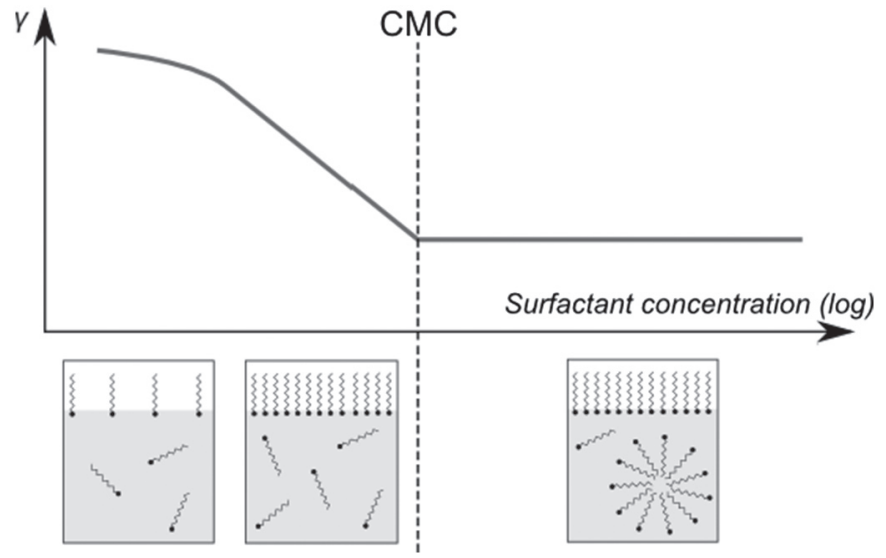

Fig. 1. Surfactant distribution and surface tension.

surface formation [5]. Length of stretched hydrocarbon chain in $\mathrm{nm}$ is related to the number of carbon atoms $n_{C}$ by [7]

$l=0.1275\left(n_{c}-1\right)+0.19+0.23$

Stretched length of a 10 carbon chain is therefore $1.57 \mathrm{~nm}$, which gives an idea of the size of these molecules compared to other organic compounds used as additives in the cement and concrete industry, namely around $5 \mathrm{~nm}$ for water reducing agents such as PCE comb copolymer coils [8-10] and around $50 \mathrm{~nm}$ for the coiled macromolecules used as viscosity agents [11].

Most organic additives for cement adsorb on the cement grain surfaces $[12,13]$. In the case of large molecules, such as poly-carboxylic ethers, adsorption of polymer coils leads to steric repulsion between grains and to a decrease in the yield stress of the suspension [14,15].

Adsorption of surfactant molecules on cement grains has been reported by $[16,17,6]$. Due to their specific molecular structure, surfactant molecules may adsorb in various configurations. Indeed, single molecules adsorption is reported to find its origin in either the hydrophilic head or the hydrophobic tail depending on the surface properties [12,13]. While in 1992, Uchikawa et al. [16] made the hypothesis that hydrophilic heads were oriented towards the bulk solution, the hypothesis of electrostatic adsorption of the head was latter most common for ionic surfactants $[17,6,13]$. Zhang et al. [17] measured adsorption on cement of three surfactants - cationic, anionic and non-ionic - and compared adsorption isotherms with contact angle on compacted cement powder pastilles (see details of a similar protocol in Section 3.2.5). They observed no adsorption with the non-ionic surfactant, whereas partial adsorption of both tested ionic surfactants was measured no matter their initial concentrations. For ionic surfactants, adsorption of ionic heads on the cement particle surface is reported to lead to an hydrophobization of the grain surface and thus to an increase of the contact angle of water on the resulting hardened material, up to a maximum value reached when the grain surface is saturated. At higher concentrations, hydrophobicity of the cement grains surface was noted to decrease in the case of anionic surfactant. This effect was explained by the formation of surfactant agglomerates at the surface of the grains. Recently, Petit et al. [18] also measured the above hydrophobicity maximum at intermediate concentrations for one anionic surfactant. The experimental procedure was the imbibition of cement powder by the surfactant solution. They observed no effect of cationic surfactant on cement surface properties.

\subsection{Foam stability}

Before cement setting and hardening, the initial pores structure obtained after mixing can get destabilized through three distinct mechanisms (Fig. 2): (1) the gravity driven flow of the paste through the rising bubbles leads to an heterogeneous distribution of air within

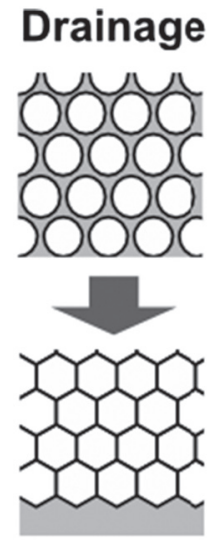

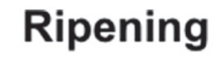

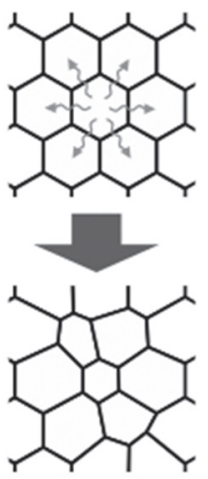

Coalescence

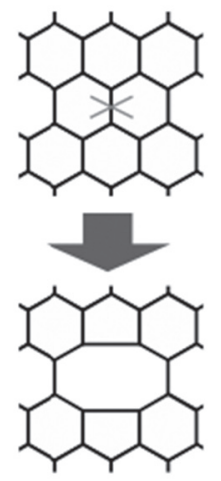

Fig. 2. Destabilization mechanisms in a foam.

the sample, (2) difference in capillary pressure between bubbles of different sizes leads to gas exchange (ripening); it leads to bubble rearrangements and a global increase of the average bubble size $R_{b}$ as a function of time, and (3) foam films breakage induces the coarsening of the bubble assembly through coalescence events. It is to note that the magnitude of the two latter mechanisms increases as the gas fraction increases, which is precisely a consequence of gravity drainage.

Bubble coalescence is generally counteracted by a significant disjoining pressure arising in thin liquid films due to the presence of surfactants at concentrations above the CMC. However, in cement pastes and more specifically in the high ionic strength interstitial fluid, the ability of common surfactants to ensure the stability of thin water films is not obvious and deserves specific investigation [6].

A relevant strategy to control the destabilizing mechanisms of a foam is to take advantage of yield stress $\left(\tau_{y}\right)$ properties of pastes [1-3]: basically, drainage stops as $\tau_{y} \sim \rho g r$, where $\rho$ is the density of the paste and $r$ is the typical size of interstices between the bubbles. Moreover, the ripening process is strongly dampened as $\tau_{y} \sim \gamma / R_{b}$, where $\gamma$ is the surface tension of the liquid/air interface. An alternative foam stabilization strategy involves particles adsorption at the bubbles surface thanks to the in-situ hydrophobization of the particles contained in the paste to be foamed $[19,18]$. No matter the strategy chosen to stabilize the foamed material, adsorption properties of surfactants at the surface of cement grains appear in all literature available as a crucial parameter.

\subsection{Yield stress of solid suspensions}

Cement paste is a suspension a solid cement grains in aqueous phase. The yield stress $\tau_{y}$ depends on the interaction of each solid particle with its closest neighbors. A relation between macroscopic yield stress and particle interaction has been proposed in the so-called Yodel [20]. In this model, the inter-particle force parameter $G(h)$ is defined as

$G(h)=\frac{F_{V d W}+F_{E S}+F_{S t e r}}{\tilde{\mathrm{a}}}$

where $F_{V d W}$ is Van der Waals attractive force between particles, $F_{E S}$ is the electrostatic interaction, $F_{S t e r}$ is the steric interaction and ã refers to the radius of curvature of the particle surface. $G$ depends on the distance $h$ between solid grains. Flatt and Bowen [20] showed that the yield stress of a suspension is proportional to the maximum value of $\mathrm{G}$, obtained at the minimal inter-particle distance.

Hence, to understand the change of yield stress with surfactant addition, analysis of the interactions between cement grains must be carried out. First, attraction due to the Van der Waals force is inversely proportional to the square of the interparticle distance: $F_{V d W} \propto 1 / h^{2}$. Thus, increasing distance between the cement grains reduces the Van der Waals interaction. Secondly, for a charged surface in an electrolyte 
solution, the range of the electrostatic force is given by the Debye length $\kappa^{-1}$. The Debye length gives the thickness of the ions layer balancing the electrostatic charge close to the solid surface. In cement paste, the Debye length is rather small because of the high ionicity of the interstitial solution, i.e. $\kappa^{-1} \simeq 0.7 \mathrm{~nm}$ [14]. Thirdly, steric interaction depends on the thickness of the layer of adsorbed molecules on grains surface. Adsorbed layers on grain surfaces can hardly interpenetrate. For instance, poly-carboxylate superplasticizers are polymers which adsorb on cement grain surface. The layer they form is at least $2.5 \mathrm{~nm}$ thick. If $h_{\text {Ster }}$ is the thickness of the layer of adsorbed molecules, steric interaction imposes $h \geq 2 h_{\text {Ster }}$. The increase of the distance between the grains leads to a lowering of the attractive Van der Waals forces and thus to fluidification of the paste.

\section{Materials and methods}

\subsection{Materials}

\subsubsection{Cement}

Cement is a CEM I from Lafarge, Saint Vigor. Specific surface provided by the manufacturer is $0.784 \mathrm{~m}^{2} / \mathrm{g}$. Chemical composition is given in Table 1.

\subsubsection{Synthetic cement pore solution}

To study the effects of ions from the cement paste on surfactants, a synthetic cement pore solution is prepared by dissolving in distilled water $1.72 \mathrm{~g} / \mathrm{L}$ of $\mathrm{CaSO}_{4} \cdot 2 \mathrm{H}_{2} \mathrm{O}, 6.959 \mathrm{~g} / \mathrm{L}$ of $\mathrm{Na}_{2} \mathrm{SO}_{4}, 4.757 \mathrm{~g} / \mathrm{L}$ of $\mathrm{K}_{2} \mathrm{SO}_{4}$ and $7.12 \mathrm{~g} / \mathrm{L}$ of $\mathrm{KOH}[21]$.

\subsubsection{Surfactants}

Surfactants are listed in Table 2 with their charge, molar mass and active content when given by the provider. Average values are presented when necessary. All of them have been used as received from the provider. Fig. 3 gathers their molecular structures.

\subsubsection{Cement paste preparation}

The cement pastes studied here have a water-to-cement ratio of 0.5. They are prepared as follows:

1. A cement paste at water-to-cement ratio 0.4 is prepared by adding cement to distilled water and is mixed by hand for $1 \mathrm{~min}$.

2. The paste rests for $20 \mathrm{~min}$ so that first hydration products (mostly sulfo-aluminates) form [21] before surfactants are added.

3. A solution of surfactant in distilled water is added, in such a way that the final water to cement ratio reaches $\mathrm{W} / \mathrm{C}=0.5$. Hence, if the surfactant concentration in the added solution is $C_{a d d}$, the concentration of the surfactant in the whole amount of water contained in the cement paste is $C_{i}=1 / 5 \times C_{\text {add }}$.

4. The paste is mixed manually and slowly to avoid any air entrainment for 5 min.

A very important point to note here is that our mixing protocol is specifically chosen in order to avoid any air entrainment or any foaming. We focus here on the role of surfactants only and we therefore chose to prepare pastes, in which the presence of a surfactant and its concentration were the only varying parameters. For some samples, we

Table 1

Chemical composition of CEM I cement from Lafarge, Saint-Vigor.

\begin{tabular}{llllll}
\hline $\mathrm{C}_{3} \mathrm{~S}$ & $\mathrm{C}_{2} \mathrm{~S}$ & \multicolumn{1}{c}{$\mathrm{C}_{3} \mathrm{~A}$} & $\mathrm{C}_{4} \mathrm{AF}$ & $\mathrm{CaO} / \mathrm{SiO}_{2}$ & $\mathrm{Al}_{2} \mathrm{O}_{3}$ \\
\hline $62.0 \%$ & $16.0 \%$ & $2.1 \%$ & $15.2 \%$ & 3 & $4 \%$ \\
$\mathrm{MgO}$ & $\mathrm{Na}_{2} \mathrm{O}+0.658 \mathrm{~K}_{2} \mathrm{O}$ & $\mathrm{SO}_{3}$ & Gypsum & L.O.I. \\
$1.1 \%$ & \multicolumn{2}{c}{$0.34 \%$} & $2.58 \%$ & $2.4 \%$ & $0.9 \%$ \\
\hline
\end{tabular}

Table 2

Surfactant properties. Molar weight is an average in the case of mixed molecules and $a_{\%}$ is the active content of the products.

\begin{tabular}{|c|c|c|c|c|}
\hline Name & Charge & $\begin{array}{l}\text { Molar mass } \\
(\mathrm{g} / \mathrm{mol})\end{array}$ & Purity $a_{\%}$ & Provider \\
\hline TTAB & + & 336 & $\geq 99 \%$ & $\begin{array}{l}\text { Sigma- } \\
\text { Aldrich }\end{array}$ \\
\hline TEGO $^{\circ}$ Betain F50 & $+1-$ & 343 & & Evonik \\
\hline SDS & - & 288 & $\geq 98.5 \%$ & $\begin{array}{l}\text { Sigma- } \\
\text { Aldrich }\end{array}$ \\
\hline Steol $^{\circ} 270$ CIT & - & 382 & $68-72 \%$ & Stepan \\
\hline Bio-Terge ${ }^{\circ}$ AS- $40 \mathrm{~K}$ & - & 315 & $39.1 \%$ & Stepan \\
\hline $\begin{array}{l}\text { Triton }^{\mathrm{TM}} \mathrm{X}-100 \text { (laboratory } \\
\text { grade) }\end{array}$ & 0 & 625 & & $\begin{array}{l}\text { Sigma- } \\
\text { Aldrich }\end{array}$ \\
\hline Brij 700 & 0 & 4670 & & $\begin{array}{l}\text { Sigma- } \\
\text { Aldrich }\end{array}$ \\
\hline Tween 20 & 0 & 1225 & $97 \%$ & Acros \\
\hline
\end{tabular}

checked a posteriori that only very few bubbles were entrained through the surfactant addition protocol either by centrifugation of the sample or by addition of small amount of the paste into distilled water. We did not visually detect any air bubbles release in these tests (results not shown here).

\subsection{Methods}

\subsubsection{Surfactant compatibility with cement pore solution}

$50 \mathrm{~mL}$ tubes are filled with $10 \mathrm{~mL}$ of solution containing $0.1 \mathrm{~g}$ of surfactant. Tubes are shaken by hand during $15 \mathrm{~s}$, then placed vertically at rest. First, precipitation in cement pore solution is visually assessed, then samples are classified according to their foaming capacity:

- 0: No foam

- + : Foam volume below $20 \mathrm{~mL}$

- ++ : Moderately stable foam

$\bullet+++$ : The tube is filled with foam for longer than $1 \mathrm{~h}$

For each surfactant, a sample prepared from the synthetic cement pore solution described in Section 3.1.2 is compared to a reference sample prepared with distilled water $(\mathrm{pH}=7)$.

\subsection{2. $C M C$}

CMC in water and in cement pore solution are obtained from surface tension measurements using the Pendant Drop Method and a Teclis tensiometer (see Fig. 1). The test consists in generating a drop of
TTAB (+)

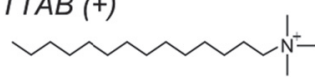

Betain (+/-)<smiles>CCCCCCCCCC(=O)N(C)CCC[N+](C)(C)CC(C)O</smiles>

SDS (-)<smiles>CCCCCCCCCCCOS(=O)(=O)O</smiles>

Steol $270(-)$

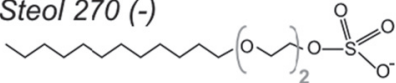

Bio-Terge (-)

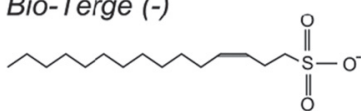

Triton $\times 100$

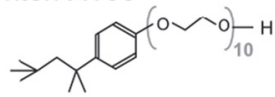

Fig. 3. Surfactant molecular structures. Bio-Terge is a mix of several molecules close to the one drawn here. 
solution at the lower end of a vertical needle. The surface tension is then computed from the drop profile, according to the Young-Laplace equation.

\subsubsection{Yield stress}

Yield stress is assessed using simple spread tests. Cement paste is poured on a horizontal flat surface. When flow stops, two perpendicular diameters of the paste deposit are measured. The yield stress is then computed from the average radius $R$, the sample volume $\omega$ and the material density $\rho$ using the following formula [22]:

$\tau_{y}=\frac{225 \rho g \Omega^{2}}{128 \pi^{2} R^{5}}$

Note that Eq. (3) is valid if the thickness of the sample is small compared to its radius and if the surface tension effects can be neglected. The second condition writes

$\tau_{y} \gg \frac{3(1-\cos \theta) \gamma}{R}$

$\theta$ is here the contact angle between the cement paste and the solid surface. $\gamma$ being smaller than the value for pure water, i.e. $70 \mathrm{mN} / \mathrm{m}$, and $\mathrm{R}$ being higher than $5 \mathrm{~cm}$ for our tests, the second term of Eq. (4) is of the order of $0.1 \mathrm{~Pa}$. Thus, all measured values computed from Eq. (3) which are below $1 \mathrm{~Pa}$ are taken equal to $1 \mathrm{~Pa}$.

\subsubsection{Adsorption}

To measure adsorption of surfactants on cement grains, we centrifuge the cement paste to collect the interstitial liquid. This liquid is filtered through a $0.45 \mu \mathrm{m}$ polypropylene filter and analyzed with a Total Organic Carbon analyser TOC $\mathrm{V}_{C S H}$ manufactured by Shimadzu.

TOC values are converted into concentration through calibration curves, which have been previously identified for each surfactant. The measured raw value is corrected by subtracting the carbon content of the cement powder due to the presence of grinding aids [21]. This gives access to the residual concentration of surfactants in the extracted interstitial liquid $C_{r}$. Adsorption value $A$ in $\mathrm{mg}$ per gram of cement is then calculated as follows: $A=\left(C_{i}-C_{r}\right) \times W / C$.

It can be noted that the relative error is large for smaller residual concentration as measured TOC values get close to the reference value due to grinding aid. Hence, all residual concentration values below $0.01 \mathrm{~g} / \mathrm{L}$ have been set to $0.01 \mathrm{~g} / \mathrm{L}$. As the smallest surfactant initial concentration is $0.1 \mathrm{~g} / \mathrm{L}$, error on adsorption value is below $10 \%$.

\subsubsection{Contact angle}

The contact angle of water on cement $\alpha$ is measured by placing a distilled water drop on a cement pastille using a tensiometer (Teclis).

To prepare the cement pastille, the cement paste is mixed as described in Section 3.1.4, then most of the water is removed either by sedimentation or by filtration. Full drying is then obtained by placing the sample in a $20^{\circ} \mathrm{C}$ and $30 \%$ humidity chamber for at least $30 \mathrm{~h}$. The resulting solid is ground into a fine powder, which is then compacted to prepare $2 \mathrm{~cm}$ diameter pastilles by applying a $210 \mathrm{MPa}$ compaction stress for $15 \mathrm{~s}$. Preliminary tests showed that increasing compaction stress from 150 to $210 \mathrm{MPa}$ reduces the penetration speed of the water into the pastille; hence, $210 \mathrm{MPa}$ stress has been chosen for all samples.

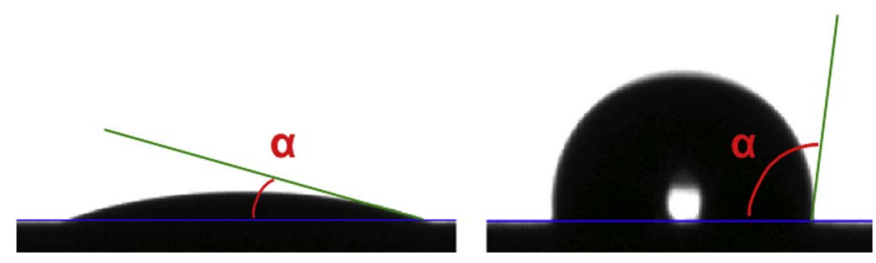

Fig. 4. Example of pictures used for contact angle measurement. Left: reference sample, $\alpha=19.6^{\circ}$; right: sample with initial concentration of Bio-Terge of $25 \mathrm{~g} / \mathrm{L}, \alpha=103^{\circ}$.
Table 3

Precipitation and foamability of surfactants in distilled water and synthetic cement pore solution.

\begin{tabular}{|c|c|c|c|c|c|}
\hline \multicolumn{2}{|c|}{ Surfactant } & \multirow[t]{2}{*}{ Precipitation } & \multicolumn{2}{|l|}{ Foam } & \multirow[t]{2}{*}{ Compatibility } \\
\hline & & & In water & In cement sol. & \\
\hline+ & TTAB & No & +++ & ++ & Yes \\
\hline$+1-$ & Betain & No & ++ & 0 & No \\
\hline- & SDS & Yes & +++ & 0 & No \\
\hline- & Steol 270 & No & +++ & +++ & Yes \\
\hline- & Bio-Terge & No & +++ & +++ & Yes \\
\hline 0 & Triton X100 & No & ++ & ++ & Yes \\
\hline 0 & Brij 700 & No & + & 0 & No \\
\hline 0 & Tween 20 & Yes & + & 0 & No \\
\hline
\end{tabular}

0 : No foam.

+ : Foam volume below $20 \mathrm{~mL}$.

++ : Moderately stable foam.

+++ : Tube filled with $40 \mathrm{~mL}$ foam for longer than $1 \mathrm{~h}$

$\alpha$ is assessed from images of the water drop as shown in Fig. 4. After the drop is set on the pastille, it fully penetrates into cement in 2 to $10 \mathrm{~s}$, even if the surface is initially hydrophobic. This may be explained by the change in surface properties due to the dissolution of adsorbed surfactant molecules into water. This specific phenomenon may lead to underestimate $\alpha$. Picture is taken $1 \mathrm{~s}$ after drop deposition and for each sample, measurement is repeated 4 times and the average value is considered.

\section{Results and discussion}

\subsection{Surfactants in synthetic cement pore solution}

Foamability of surfactant solutions in water and in cement pore solution are summarized in Table 3. For the latter case, the table reports whether a precipitate was observed.

For some surfactants, foam could not be obtained in presence of the synthetic cement pore solution while foam could be generated with the same surfactant in distilled water. Among them, SDS and Tween 20 precipitated when added to the cement solution. This observation for SDS is in agreement with results reported by Jolicoeur [23], who noticed that there is no residual surfactant in solution when SDS is added to a cement paste, even at high surfactant dosage. Note however that air bubbles have been successfully entrained in the cement pastes containing SDS in $[23,24]$. Some authors $[23,4]$ suggested that the insoluble surfactant - calcium salts enhance stabilization of the bubbles. Similar conclusion was obtained by Tunstall et al. [25], who observed the complexation of some commercial air-entraining agents in their synthetic cement pore solution. Besides, Petit et al. [18] observed a modification of the surface properties of cement grains when adding SDS to a cement paste, suggesting that, at the low concentration they studied, some SDS molecules did not precipitate but adsorbed on cement grain surface.

Regarding Betain and Brij 700, even if no precipitate could be visually observed, no foam could be generated in the synthetic cement pore solution. One hypothesis to explain the incompatibility of Betain and Brij 700 with cement solution is the formation of soluble complexes with ions (calcium, sulfate...).

The other four surfactants are compatible with the cement solution: one of them is cationic (TTAB), two are anionic (Steol and Bio-Terge) and one is non-ionic (Triton). In the following, we will focus on these four surfactants.

Surface tension was measured for distilled water and synthetic cement pore solution without surfactant. In both cases, it was around $71 \mathrm{mN} / \mathrm{m}$. Fig. 5 gives the surface tension curves for all four compatible surfactants. On the $\mathrm{X}$-axis, concentration refers to the total surfactant mass added to the solution whether they are under liquid or solid form, 


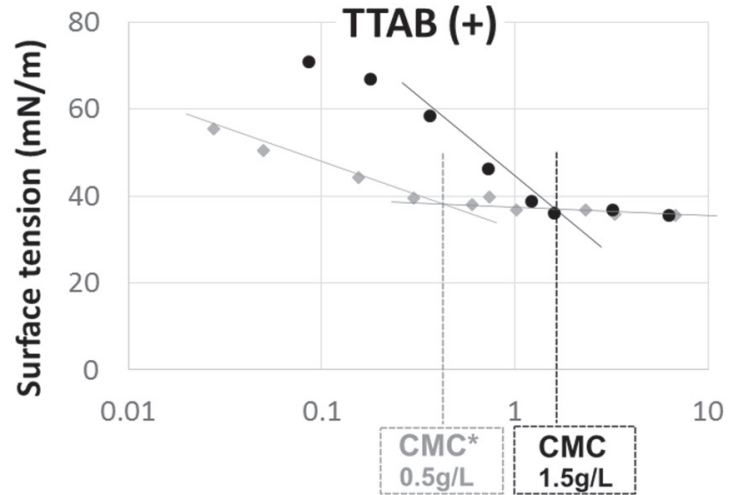

Concentration (g/L)

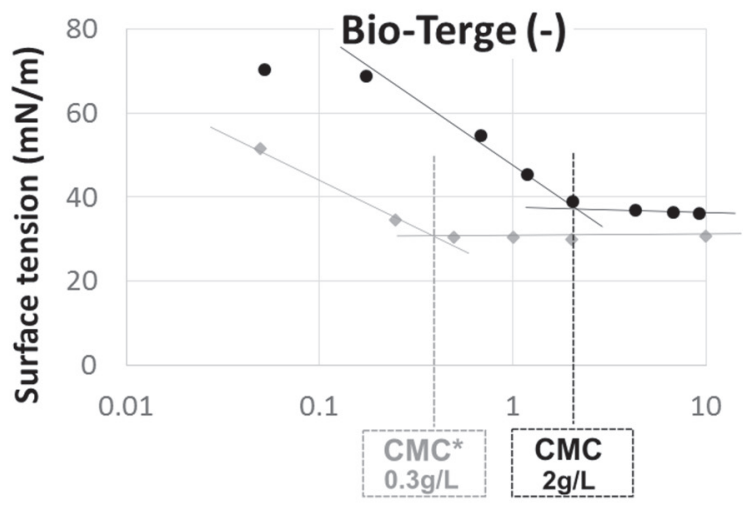

Concentration $(\mathrm{g} / \mathrm{L})$
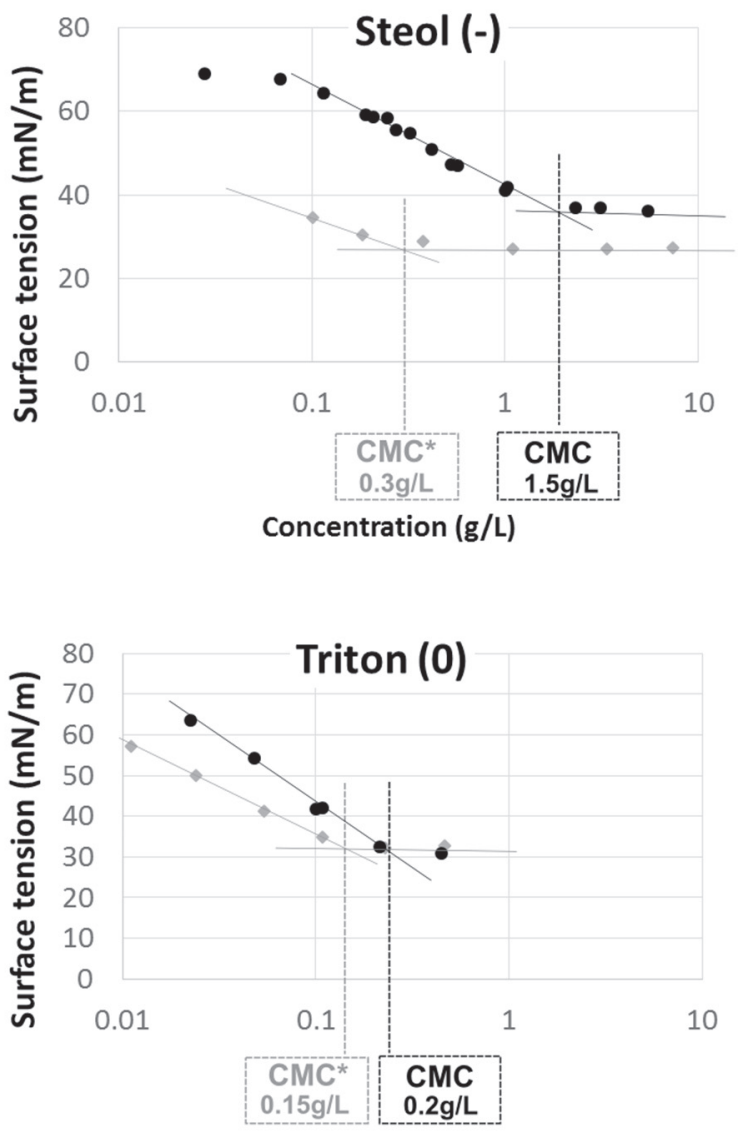

Concentration $(\mathrm{g} / \mathrm{L})$

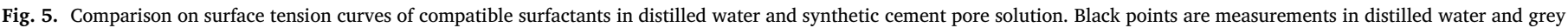
squares are values in synthetic cement pore solution.

which means that it includes some water in the case of Steol and BioTerge solutions (see Table 2).

The cement solution has a strong effect on the surface tension of solutions containing ionic surfactants. Because of the high ion content, electrolyte solution reduces the range of the electrostatic repulsion between surfactant charged heads [5]. Therefore, surfactant density increases at gas-water interfaces, which leads to a decrease of the surface tension. As expected, this reduction is found to be small for nonionic Triton. Tunstall et al. [25] observed, with some of the anionic surfactants they tested, an increase of surface tension in alkaline solutions containing calcium ions. This effect was related to the loss of surfactant molecules available to settle at air-water interface due to the formation of complexes with calcium ions. This effect is not observed in Fig. 5 because the chosen surfactants are not affected by calcium ions.

CMC are deduced from these curves as the intersection of two straight lines, each of them being representative of the surfactant effect before and after the CMC. In the following, the CMC measured in the synthetic cement pore solution is noted CMC*. All extracted CMC in

Table 4

CMC in distilled water and $\mathrm{CMC}^{*}$ in synthetic cement pore solution. Values give weight of the surfactants as sold by the providers.

\begin{tabular}{lll}
\hline Surfactant & CMC & CMC* \\
\hline TTAB (+) & $1.5 \mathrm{~g} / \mathrm{L}$ & $0.5 \mathrm{~g} / \mathrm{L}$ \\
Steol (-) & $1.5 \mathrm{~g} / \mathrm{L}$ & $0.3 \mathrm{~g} / \mathrm{L}$ \\
Bio-Terge (-) & $2 \mathrm{~g} / \mathrm{L}$ & $0.5 \mathrm{~g} / \mathrm{L}$ \\
Triton (0) & $0.2 \mathrm{~g} / \mathrm{L}$ & $0.15 \mathrm{~g} / \mathrm{L}$ \\
\hline
\end{tabular}

water and $\mathrm{CMC}^{*}$ are given in Table 4. For all ionic surfactants, CMCs are lower in synthetic cement pore solution than in distilled water solutions whereas it stays almost constant for the non-ionic surfactant. Indeed, reduction of the electrostatic force range favors the agglomeration of ionic surfactant molecules into micelles.

It is worth noting that electrostatic repulsion between surfactant layers may contribute to the stabilization of liquid films in foams. As a consequence, the above screening of these forces may be at the origin of the faster destabilization of the TTAB foam in cement solution reported in Table 3 as well as the inability of Betain to form foam with the synthetic cement solution.

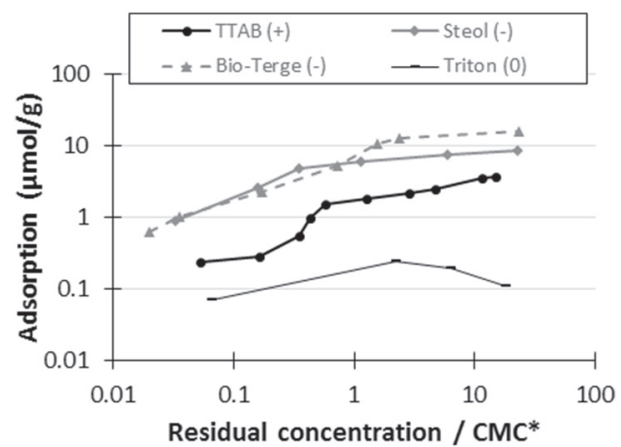

Fig. 6. Comparison of adsorption isotherms of compatible surfactants. On Y-axis, adsorption is given in $\mu \mathrm{mol}$ per gram of cement and on $\mathrm{X}$-axis, residual concentration is divided by the CMC* in synthetic cement pore solution (see Table 4). 


\subsection{Adsorption sites and surfactant distribution}

Adsorption isotherms for the four compatible surfactants are given in Fig. 6.

First, let us note the difference of maximum adsorption for the surfactants. Measured maximal adsorption is, for one gram of cement, $4.6 \mathrm{mg}$ of Steol and $13 \mathrm{mg}$ of Bio-Terge, that is to say respectively $8.5 \mu \mathrm{mol}$ and $16 \mu \mathrm{mol}$. Maximum adsorption of TTAB is $3.7 \mu \mathrm{mol}$ $(1.3 \mathrm{mg})$ per gram of cement. As mentioned in Section 3.1.4, surfactants are added to the cement paste $20 \mathrm{~min}$ after the first contact between cement and water. At this time, solid surfaces in solution are hydroxylate surfaces of clinker phases, mainly $\mathrm{C}_{3} \mathrm{~S}$ and $\mathrm{C}_{2} \mathrm{~S}$, and first hydration products, C-S-H, ettringite and portlandite. In high electrolyte solution like cement pore solution, calcium ions adsorb on negatively charged silicate surfaces $\left(\mathrm{C}_{3} \mathrm{~S}, \mathrm{C}_{2} \mathrm{~S}, \mathrm{C}-\mathrm{S}-\mathrm{H}\right.$ and portlandite), resulting in positive zeta potential [26]. On the other hand, sulfate ions adsorbed on ettringite provide for negative zeta potential [26]. The diversity of solid surfaces accounts for the different affinities of cationic and anionic surfactants.

Very low adsorption is measured for non-ionic Triton X100 (maximum $0.12 \mathrm{mg} / \mathrm{g}$ or $0.19 \mu \mathrm{mol} / \mathrm{g}$ ), which is consistent with previous measurements of adsorption with this surfactant [17].

Isotherms of Steol, Bio-Terge and TTAB in Fig. 6 can be compared with adsorption isotherms of ionic surfactant from the literature. Such adsorption has indeed been extensively studied [27-31] on silica or metal oxides. Typical adsorption isotherm comprises four regimes (Fig. 7): (1) isolated molecules adsorb "head on" thanks to electrostatic attraction, (2) adsorption rate increases due to favorable hydrophobic interactions with tails of previously adsorbed molecules, (3) starting from a residual concentration called hemimicelle concentration (HMC) surface agglomerates form by attraction of the hydrophobic tails on hydrocarbon chains of the first layer of molecules. (4) At residual concentrations close to the CMC, adsorption reaches a plateau. This plateau may have two origins: first, free molecule concentration varies slowly above CMC and micelles do not adsorb on the surface $[27,30]$ (pseudophase separation model), and secondly, the solid surface may be saturated with surface agglomerates (Fig. 7).

The above four regimes cannot be clearly identified on Steol, BioTerge and TTAB isotherms on Fig. 6. Main difference between cement and model systems from the literature are the diversity in potential adsorption sites in cement paste, to which one given surfactant may have different affinities, making the dissociation of adsorption regimes difficult. Though, we can observe that, for all of these three molecules,

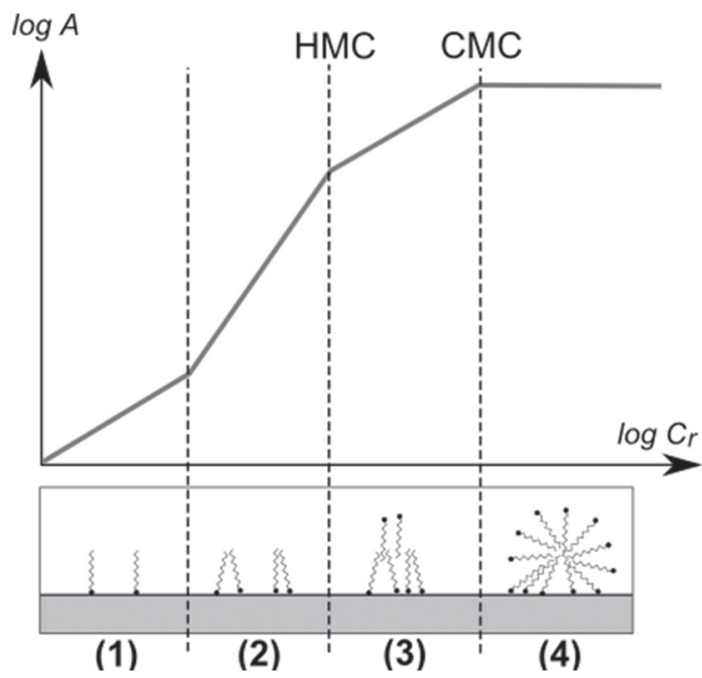

Fig. 7. Four regimes model for adsorption of ionic surfactants on oppositely charged surfaces.

Source: Schema is adapted from $[29,30]$.
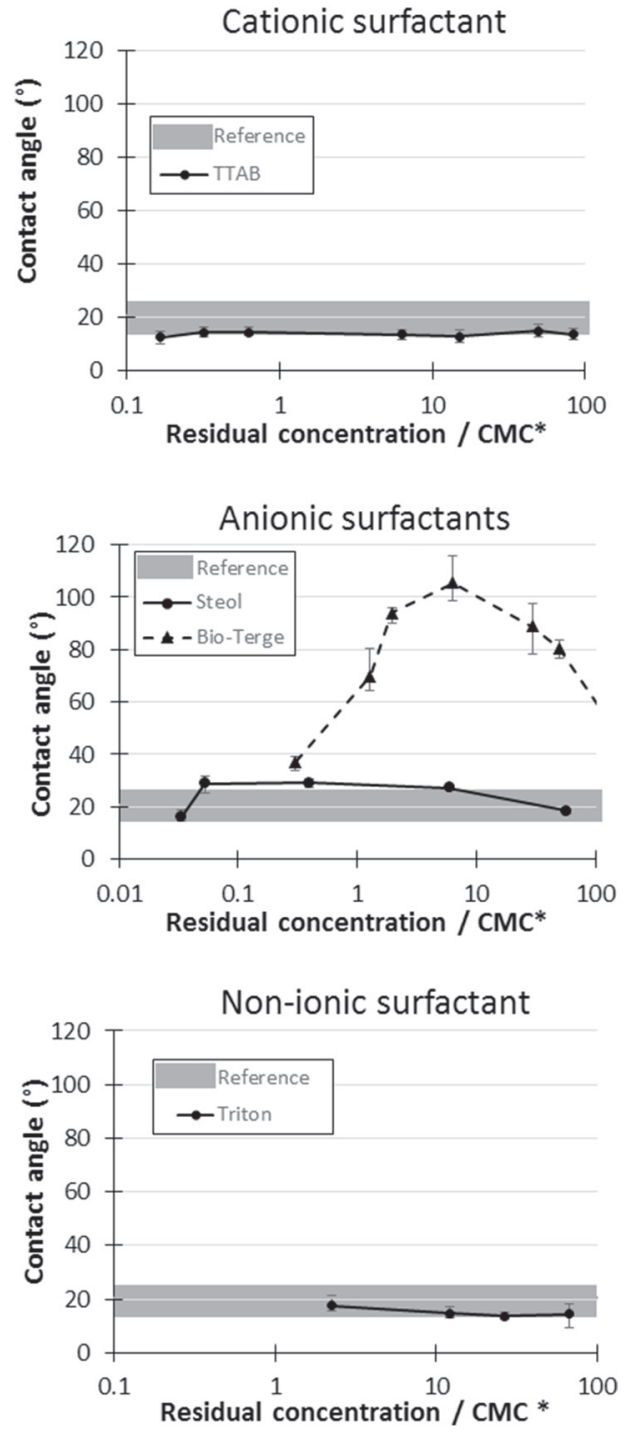

Fig. 8. Contact angle of cement surface after surfactant adsorption.

the adsorption plateau is indeed reached close to the CMC*.

Regarding cationic TTAB, at lowest concentrations, adsorption is very low so that initial slope is close to zero and adsorption isotherm has an S-shape. S-shaped adsorption isotherms have been simulated by Zhu and $\mathrm{Gu}$ [31] for systems where the equilibrium constant of the formation of surface agglomerates is high compared to the constant related to the adsorption of one molecule. In other words, in systems simulated by Zhu et al., an adsorbed molecule hardly remains alone. This translates in a very low adsorption of single molecules at low concentrations and a brutal rise in adsorption as soon as concentration allows for the formation of agglomerates.

Contact angle of cement grain surface are plotted as a function of surfactant concentration in Fig. 8.

For the reference sample, measurement has been carried out on 4 different cement pastilles. The 15 obtained contact angle values range from $11^{\circ}$ to $34^{\circ}$ with average value $21^{\circ}$ and standard deviation $7^{\circ}$ (i.e. $33 \%$ of the average value).

Regarding samples containing surfactant, the drop imbibition takes more time, probably because surfactant dissolution is required prior to imbibition. For each surfactant concentration, contact angle is measured on four different drops. Error bars in Fig. 8 give the highest and the lowest of the four values. They provide for an estimation of the error related to the time of the measurement. Maximum relative error is $15 \%$ of the contact angle for both anionic surfactants (Steol and Bio- 
Terge), 20\% for cationic TTAB and 30\% for Triton. Relative errors are smaller when surfactant adsorption is higher, which tends to show that drop imbibition is delayed because of the surfactant desorption time.

Anionic surfactants increased the contact angle up to a maximal contact angle at intermediate concentrations. No change of contact angle was observed for samples containing TTAB or Triton.

Contact angle curves for anionic surfactants are consistent with previous results from literature [17]. They confirm that surface agglomerates form at residual concentration close to $\mathrm{CMC}^{*}$. Indeed, contact angle increases at low concentrations indicating that a monolayer of surfactant forms on cement grain surface. In this concentration range, molecules heads adsorb through electrostatic interaction and hydrocarbon chains are oriented outwards. Contact angle increases as the number of adsorbed molecules increases. In the higher concentration range, reduction of contact angle shows that orientation of the additional molecules is opposite: hydrophilic heads are oriented towards the solution.

Contact angle for TTAB cationic surfactant is constant. Eventually, contact angle measurement and adsorption isotherm shape both seem to show that during adsorption of TTAB, adsorbed molecules tend to agglomerate even at low concentrations while the amount of free molecules adsorbed at low concentrations is too low to affect contact angle.

\subsection{Relation between yield stress and adsorbed surfactant}

Yield stress measurements of the reference paste without surfactant were repeated three times. The average value was $11.9 \mathrm{~Pa}$ and the standard deviation was $0.6 \mathrm{~Pa}$. Results for surfactant containing samples are given in the graphs of Fig. 9.

Results presented in Fig. 9 show a drop in yield stress down to below 1 Pa above a concentration threshold for two surfactants: Steol and BioTerge. A slight yield stress reduction, down to half the reference value, is also observed for TTAB. At low concentration range, a large increase in yield stress is observed for Bio-Terge, and a small increase for Steol. It remains close to the reference paste value for all other surfactants. No variation of yield stress is observed for Triton, which is consistent with the very low adsorption and the absence of contact angle variations.

We note $\mathrm{C}_{\text {Crit }}$ the critical residual concentration between higher yield stress regime and low yield stress regime. It is for all three ionic surfactants close to $\mathrm{CMC}^{*}$.

\subsubsection{Yield stress drop at high concentration range}

Fig. 9 shows that, for Steol and BioTerge, yield stress drops drastically above $\mathrm{C}_{\text {Crit }} \simeq \mathrm{CMC}^{*}$ the adsorption plateau is reached and the contact angle is maximal, i.e. when surfactants agglomerate on cement grains surfaces. Besides, using the light scattering method, the typical diameters of Steol and Bio-Terge micelles in synthetic cement pore solution were measured to be around $10 \mathrm{~nm}$. It is one order of magnitude above the Debye length $\kappa^{-1} \simeq 0.7 \mathrm{~nm}$ [14], which means that these adsorbed micelles are large enough to increase inter-particle distance through steric repulsive interactions. We can then suggest that drop in yield stress is due to steric repulsion between cement grains related to the agglomeration of adsorbed surfactant molecules.

Lower amounts of TTAB are adsorbed compared to anionic surfactants, so that some surfaces are not covered by TTAB. This may cause the lower reduction of yield stress observed for this surfactant above $\mathrm{C}_{\text {Crit }} \simeq \mathrm{CMC}^{*}$. Besides, TTAB micelle typical size measured in synthetic cement pore solution is slightly smaller than other surfactants, i.e. $5 \mathrm{~nm}$.

\subsubsection{Yield stress increase at low concentration range}

Regarding concentrations below the threshold, for both anionic surfactants, the yield stress increases. A previous study showed a $40 \%$ increase of dynamic viscosity due to added anionic surfactants (SDS, sodium abietate and petroleum sulfonate) at low concentration, i.e.

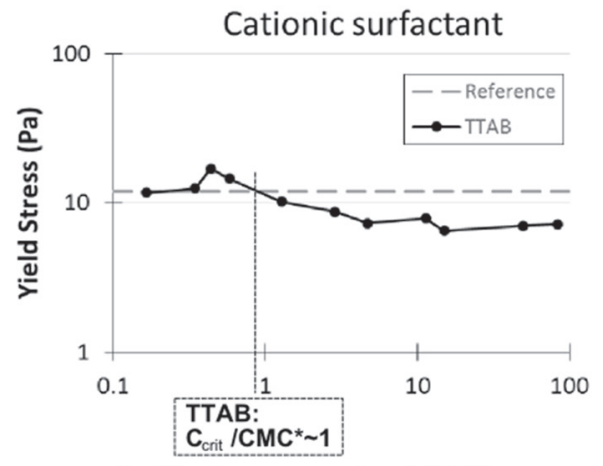

Residual concentration / CMC*
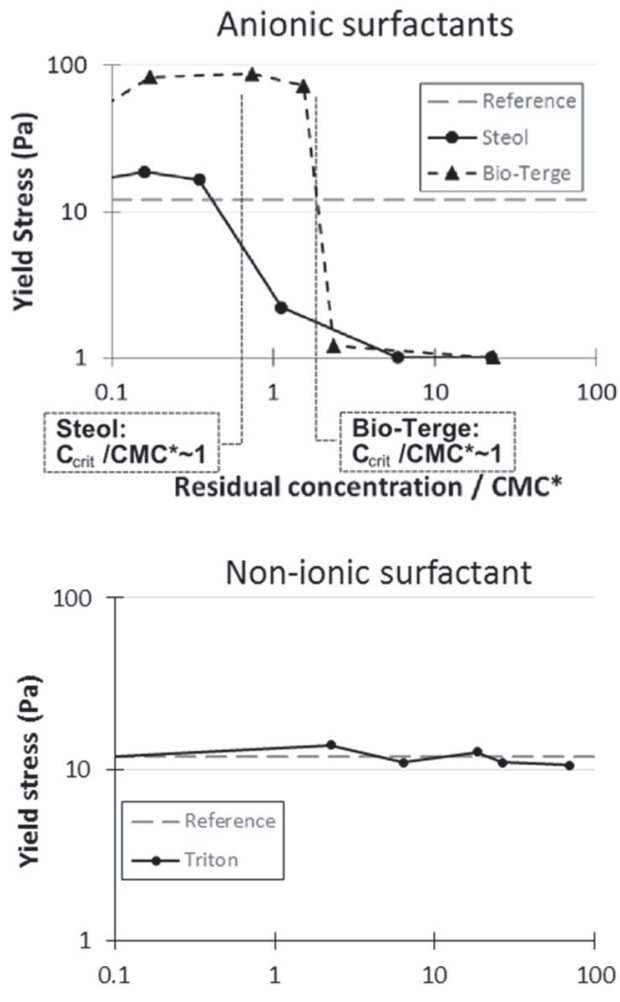

Residual concentration / $\mathrm{CMC}^{*}$

Fig. 9. Yield stress results of compatible surfactants on cement.

$0.1 \mathrm{wt} \%$ of cement [32]. As a comparison, in the present study the yield stress drops when the initial concentrations of Steol and Bio-Terge are above respectively 0.3 and $1 \mathrm{wt} \%$. The present results shed new light on results from [32]: at low shear rate $\dot{\gamma}$, the apparent viscosity $\eta$ of yield stress fluid is related to the yield stress by $\eta \sim \tau_{y} / \dot{\gamma}$, therefore, a relative increase of $\tau_{y}$ leads to the same relative increase of $\eta$.

We have already mentioned that, in the residual concentration regime below CMC*, a single layer of adsorbed molecules turns the grains surface hydrophobic. Several authors have shown that hydrophobic surfaces tend to attract each other [33,34]. This hydrophobic interaction is for instance the driving mechanism for the formation of surfactant micelles in solution [34].

The force between two hydrophobic surfaces $F_{H}$ can be estimated from the radius of curvature of the surface ã and the surface tension between water and hydrocarbons $\gamma_{H}$ [33] at the distance $\mathrm{h}$ where both hydrocarbon layers are in contact:

$F_{H}=2 \pi \tilde{\mathrm{a}} \gamma_{H}$

The irregular shape of cement grains makes the radius of curvature 
ã difficult to estimate. Though $F_{H}$ can be compared with van der Waals force, which is also proportional to ã $[33,35,20]$ :

$F_{V d W}=\frac{1}{12} A(h)\left(\frac{\tilde{\mathrm{a}}}{h^{2}}\right)$

At separation distance of a few nanometers, Hamaker constant A(h) is close to the reference value $\mathrm{A}(0)$, which is of the order of magnitude of $10^{-20} \mathrm{~J}$ in cement pastes [35]. In addition, the order of magnitude of $\gamma_{H}$ is $10^{-2} \mathrm{~J} / \mathrm{m}^{2}$ [33]. The ratio of hydrophobic to van der Waals interactions can be roughly estimated as

$F_{H} / F_{V d W} \sim 24 \pi h^{2} \gamma_{H} / A(0) \sim 10^{2}$

This shows that hydrophobic attractive interaction potentially dominates van der Waals attractive forces between hydrophobic particles at separation distance above $\mathrm{h}=2 \mathrm{~nm}$.

Number of carbons in hydrocarbon chains of surfactant molecules are 12 for Steol and 14 to 16 for Bio-Terge. Estimation of their length with formula (1) gives thus $1.8 \mathrm{~nm}$ for Steol and $2.2 \mathrm{~nm}$ for Bio-Terge. Either this length difference or simply the higher local hydrocarbon density may explain why the yield stress increase is larger with BioTerge.

\section{Conclusion}

We observed in this work several distinct behaviors for surfactants when they are introduced into a cement paste:

1. precipitation, which in turn leads to loss of foamability of the molecule,

2. adsorption on cement grains surface and

3. no interaction with cement grains.

In case (2), the surfactant noticeably affect the rheology of the cement paste. At low concentration, i.e. below a critical residual concentration $\mathrm{C}_{\text {Crit }}$, molecules adsorb head on. Hydrophobic forces between tails results in most cases in an increase of the yield stress with respect to the surfactant-free paste. At high concentration range, above $\mathrm{C}_{\text {Crit }}$, the formation of large surface agglomerates is at the origin of a brutal decrease in yield stress due to steric hindrance.

To manufacture a cement foam, the low concentration regime $\mathrm{C}_{r}<\mathrm{C}_{\text {Crit }}$ could be promising. First, high yield stress values enhances foam stabilization. In addition, surfactant monolayer induces hydrophobization of cement grains, and hydrophobic particles are known to stabilize liquid films by setting at air-water interfaces.

\section{Acknowledgments}

This work has benefited from two French government Grants managed by the Agence Nationale de la Recherche [Grant numbers ANR-11-LABX-022-01 and ANR-13-RMNP-0003-01]. The authors thank Géraldine Vue from Laboratoire Navier for support to make pastilles for contact angle measurements.

\section{References}

[1] S. Guignot, S. Faure, M. Vignes-Adler, O. Pitois, Liquid and particles retention in foamed suspensions, Chem. Eng. Sci. 65 (2010) 2579-2585.

[2] I. Lesov, S. Tcholakova, N. Denkov, Factors controlling the formation and stability of foams used as precursors of porous materials, J. Colloid Interface Sci. 426 (2014) 9-21.

[3] I. Lesov, S. Tcholakova, N. Denkov, Drying of particle-loaded foams for production of porous materials: mechanism and theoretical modeling, RSC Adv. 4 (2014) $811-823$.

[4] G. Gelardi, S. Mantellato, D. Marchon, M. Palacios, R. Eberhardt, A.B. an d Flatt, Science and technology of concrete admixtures, Chemistry of Chemical Admixtures, Woodhead Publishing, 2016, pp. 149-218.

[5] I. Cantat, S. Cohen-Addad, F. Elias, F. Graner, R. Höhler, O. Pitois, F. Rouyer, A. Saint-Jalmes, Foams - Structure and Dynamics, Oxford University Press, 2013.

[6] L. Du, K. Folliard, Mechanisms of air-entrainment in concrete, Cem. Concr. Res. 35 (2005) 1463-1471.

[7] B. Cabane, S. Hénon (Eds.), Liquids: Solutions, Dispersion, Émusions, Gels, Belin, 2003.

[8] P. Borget, L. Galmiche, J. Le Meins, F. Lafuma, Microstructural characterisation and behaviour in different salt solutions of sodium polymethacrylate-g-PEO comb copolymers, Colloids Surf. A. Physiochem. Eng. Asp. 260 (2005) 173-182.

[9] J. Hot, H. Bessaies-Bey, C. Brumaud, M. Duc, C. Castella, N. Roussel, Adsorbing polymers and viscosity of cement pastes, Cem. Concr. Res. 63 (2014) 12-19.

[10] G. Gelardi, N. Sanson, G. Nagy, R. Flatt, Characterization of comb-shaped copolymers by multidetection SEC, DLS and SANS, Polymers 9 (2017) 61.

[11] C. Brumaud, H. Bessaies-Bey, C. Mohler, R. Baumann, M. Schmitz, M. Radler, N. Roussel, Cellulose ethers and water retention, Cem. Concr. Res. 53 (2013) 176-184.

[12] C. Jolicoeur, M.-A. Simard, Chemical admixture-cement interactions: phenomenology and physico-chemical concepts, Cem. Concr. Res. 20 (1998) 87-101.

[13] D. Marchon, S. Mantellato, R. Eberhardt, A.B. an d Flatt, Science and technology of concrete admixtures, Adsorption of Chemical Admixtures, Woodhead Publishing, 2016, pp. 219-256.

[14] R. Flatt, I. Schober, Understanding the rheology of concrete, Superplasticizer and the Rheology of Concrete, Woodhead publishing, 2012, pp. 144-208.

[15] A. Perrot, T. Lecompte, H. Khelifi, C. Brumaud, J. Hot, N. Roussel, Yield stress and bleeding of fresh cement pastes, Cem. Concr. Res. 42 (2012) 937-944.

[16] H. Uchikawa, S. Hanehara, T. Shirasaka, D. Sawaki, Effect of admixture on hydration of cement, adsorptive behavior of admixture and fluidity and setting of fresh cement paste, Cem. Concr. Res. 22 (1992) 1115-1129.

[17] T. Zhang, S. Shang, F. Yin, A. Aishah, A. Salmiah, T. Ooi, Adsorptive behavior of surfactants on surface of Portland cement, Cem. Concr. Res. 31 (2001) 1009-1015.

[18] P. Petit, I. Javierre, P.-H. Jézéquel, A.-L. Biance, Generation and stability of bubbles in a cement based slurry, Cem. Concr. Res. 60 (2014) 37-44.

[19] K. Ramamurthy, E. Kunhanandan Nambiar, G. Indu Siva Ranjani, A classification of studies on properties of foam concrete, Cem. Concr. Res. 31 (2009) 388-396.

[20] R. Flatt, P. Bowen, Yodel: a yield stress model for suspensions, J. Am. Cer. Soc. 89 (4) (2006) 1244-1256.

[21] H. Bessaies-Bey, Polymères et propriétés rhéologiques d'une pâte de ciment: une approche physique générique (Ph.D. thesis), Université Paris-Est - SIE, 2015.

[22] N. Roussel, P. Coussot, Fifty-cent rheometer for yield stress measurements: from slump to spreading flow, J. Rheol. 49 (3) (2005) 705-718.

[23] C. Jolicoeur, T. To, T. Nguyen, R. Hill, M. Pagé, Mode of action of anionic surfactants for air entrainment in cement pastes w-W/o fly ash, 2009 World of Coal Ash (WOCA) Conference - May 4-7, 2009 in Lexington, KY, USA, 2009.

[24] H. Atahan, J.C. Carlos, S. Chae, P. Monteiro, J. Bastacky, The morphology of entrained air voids in hardened cement paste generated with different anionic surfactants, Cem. Concr. Compos. 30 (2008) 566-575.

[25] L. Tunstall, G. Scherer, R. Prud'homme, Studying AEA interaction in cement systems using tensiometry, Cem. Concr. Res. 92 (2017) 29-36.

[26] A. Zingg, F. Winnefeld, L. Holzer, J. Pakusch, S. Becker, L. Gauckler, Adsorption of polyelectrolytes and its influence on the rheology, zeta potential, and microstructure of various cement and hydrate phases, J. Colloid Interface Sci. 323 (2008) 301-312.

[27] F. Scamehorn, R. Schechter, W. Wade, Adsorption of surfactants on mineral oxide surfaces from aqueous solutions, J. Colloid Interface Sci. 85 (2) (1982) 463-478.

[28] L. Koopal, E. Lee, M. Böhmer, Adsorption of cationic and anionic surfactants on charged metal oxide surfaces, J. Colloid Interface Sci. 170 (1995) 85-97.

[29] R. Atkin, V. Craig, E. Wanless, S. Biggs, Mechanism of cationic surfactant adsorption at the solid-aqueous interface, Adv. Colloid Interf. Sci. 103 (2003) 219-304.

[30] S. Paria, K. Khilar, A review on experimental studies of surfactant adsorption at the hydrophilic solid-water interface, Adv. Colloid Interf. Sci. 110 (3) (2004) 75-95.

[31] B. Zhu, T. Gu, Surfactant adsorption at solid-liquid interfaces, Adv. Colloid Interf. Sci. 37 (1991) 1-32.

[32] R. Rixom, N. Mailvaganam, Chemical Admixtures for Concrete, third, E. \& F.N. Spon Ltd, 1999 (p106+).

[33] J. Israelachvili, R. Pashley, Measurement of the hydrophobic interaction between two hydrophobic surfaces in aqueous electrolyte solutions, J. Colloid Interface Sci. 98 (2) (1984).

[34] E. Meyer, K. Rosenberg, J. Israelachvili, Recent progress in understanding hydrophobic interactions, PNAS 103 (43) (2006) 15739-15746.

[35] R. Flatt, Dispersion forces in cement suspensions, Cem. Concr. Res. 34 (2004) $399-408$. 